\title{
After Cairo and before (and after) Beijing:

\author{
Sexual and Reproductive Health as a Part of the \\ Empowerment of Teenage Girls and Women
}

\author{
KATARINA LINDAHL \\ Director \\ International Affairs, RFSU \\ Stockholm, Sweden
}

\begin{abstract}
Empowerment of women in the perspective of sexual and reproductive health (SRH) are dealt with in this article. The themes of the Cairo and Beijing conferences are related and the discussions and conflicts regarding the SRH field commented on. The Cairo conference was a step forward seen from women's aspects - for issues concerning sexual and reproductive health.
\end{abstract}

Keywords: empowerment, women, sexual and reproductive health, Cairo and Beijing conferences

In this text I will compare the document, Programme of action, from the UN Conference on Population and Development (ICPD) in Cairo 1994, with the draft document, Platform for Action, for the Fourth World Conference on Women, held in Beijing in 1995.

The Cairo Conference marked a turning point for women's issues and sexual and reproductive rights. For the first time, reproductive rights were internationally recognized by governments. The conference resulted in a new approach to population issues, concentrating on individual needs and human development. After Cairo, there were great hopes that the conference in Beijing would go even further.

- Empowerment of women

- Gender

- Rights

were prestige words, formally expressed by nearly all governments (mostly by men) in speeches in Cairo. Before Beijing, when governments had the opportunity to concretize, they hesitated to take the first step towards real empowerment of women. In relation to the draft for Beijing, governments in some Muslim countries, at preparatory meetings, would not even accept the word gender, and rights seemed to be a dangerous word.

In Cairo, sexual and reproductive health ( $\mathrm{SRH})$ issues were the most controversial ones, and here the greatest steps forward were taken. The discussion was intense and the Vatican tried vigorously to stop "new language" in areas like safe and legal abor- 
tion, sex education, etc. But they did not succeed. In spite of the strong opposition the final document deals with areas such as women's empowerment and SRH for both adults and adolescents. The rights of the girl child are mentioned as well as male responsibility in the field of sexuality and reproduction and the need for resources for sexual and reproductive health.

The most controversial statements were those on youth and their rights. After Cairo there was hope that Beijing would express the hopes and demands of young people. Today this seems to be a vain hope. The question is whether the Beijing document will lead us backwards compared to Cairo. We now have to defend the Cairo language instead of developing it further. At the NGO Forum in Cairo, young people agreed on a resolution demanding sex education for all, and especially for young people.

UN documents do not change the world, but if they are good they can be a useful tool for those who want to positively influence the conditions of people's lives. And if they are bad, they can be a tool for those who do not want to change anything at all.

I will concentrate on those parts in the Cairo document and the draft for Beijing that are important for the empowerment of individual women and those that concern youth.

\section{The situation before Beijing}

After the last Preparatory Committee meeting (Prep Com 3) for Beijing, held in March 1995, there was agreement on only $60 \%$ of the draft for the document and this was a big problem. Usually at least $90 \%$ should be agreed on in advance if the conference is to be successful. (In the UN, text that is not agreed on is put in parentheses, and what is in these parentheses are the only parts of the documents that are negotiated.)

Why were we in this position before Beijing? The Vatican State and its friends seemed to be against the conference and they showed this by creating as many obstacles as possible. One could have expected that the Vatican state with its eight hundred male inhabitants ought to have understood that they should not interfere deeply in the conference on women's issues. The way they acted was quite the opposite. We now face a conflict that is different from earlier more common East/West or North/South conflicts. This is a conflict between the "State of God" and the "Secularized state", i.e., the same debate and conflict as in the sixteenth century.

We can ask whether all the resources the Vatican put into this conference showed a sign of weakness or strength. I think that the former is more likely. The Vatican mobilized a lot of resources in order to gain influence. Having lost so much in Cairo the Vatican wanted to stop any further advancement of the Cairo language. This could be done by means of filibustering, as in Prep Com 3 for Beijing, and by forcing agreements that weaken the document. And then in the end there was a risk that they would not sign the document anyway.

The Beijing conference received fewer resources compared to Cairo. This applied to resources from the UN, Sweden, and other countries. This might be because nobody expected the resistance to be as heavy as it was, or because this conference was not considered to be as interesting and important as the other. And there was not much joint Nordic planning for this conference either, as was the case in Cairo. The EU was one important player together with G 77. What they agreed on had influence on the document. When the Vatican put forward actions, there was not sufficient organized resistance to stop them. This time the Vatican not only concentrated on SRH but asked for the floor on all the different paragraphs and they succeeded, from their point of view, quite well in the preparatory process. 
A lot of language from the Cairo document was in parentheses and had to be negotiated once more. In Beijing it was a question of defending successes already gained, and there was a risk that the conference would end up at least one step back compared to what could have been achieved.

Consensus is the way the UN always tries to make decisions, as it is regarded as the most forceful way to do so. The ICPD Platform for Action was accepted through consensus, meaning that the absolute majority of governments agreed to it. Only a handful made reservations about different parts. But a handful of governments can also be successful in their intention to stop agreements. This was shown during the Preparatory Committee meeting for Beijing.

In connection with both conferences there was a valuable planning and preparatory process that made people aware of the importance of SRH, empowerment and the necessity for supporting youth. Hopefully this can lead to action. But it is vital to stress that if the work shall ever have any influence on young people's lives, NGOs must be regarded as important counterparts.

ICPD expressed the need for an integrated approach to SRH, including fertility regulation and a broad range of vital health needs, such as safe motherhood and the prevention of sexually transmitted diseases (STD) including HIV. The ICPD had a holistic view and pointed out the relation between health and the need for empowerment in other parts of life. The document also particularly stressed the gender perspective and pointed out the need for men to take a more active interest in issues concerning SRH. The needs and the rights of young people were also recognized in terms of information and services which would enable them to have a responsible sexual life

The question of sex education was very controversial and created intense discussions. But even though SRH rights were brought several steps forward, there is still a lot to do. After Cairo there were great expectations that important parts of empowerment would advance further in Beijing. Cairo was only the first step.

\section{Some key issues in the draft for Beijing}

A large number of the following comparisons of the Cairo and Beijing documents have been taken from an analysis made by Family Care International (FCI), New York, in June 1995. In this text it is not possible to go through all the different sets of parentheses in the document. I will just highlight the trend in the draft and point out the major differences between the two documents and between the majority and the minority.

Human rights of women are being undermined by clauses such as universally recognized or universal rights. When the concept of human rights was first formulated by the UN about fifty years ago, the question of human rights related to sexuality and reproduction was especially important for women. During the last five years these have been discussed at the Conference on human rights in Vienna, at the Conference on Population and Development in Cairo, and at the Social Summit in Copenhagen. When the draft for Beijing chose to use terminology from the time before these conferences, then this is a sign of not wanting to admit that rights related to sexuality and reproduction are also human rights. This can seem to be just a question of words, but it has certain implications. When the draft uses the terminology "universally recognized" or "universal rights" this is an attempt to limit human rights to only those legally bound to the UN convention.

These are good instruments but were adopted long before the international community recognized the rights of women as human rights. This was agreed by the in- 
ternational community e.g., in the Human Rights Conference in Vienna 1994, at ICPD in Cairo 1994, and the Social Summit in Copenhagen 1995.

\section{The commitment to adolescents}

The commitment to adolescents ' needs are being weakened by clauses stating $p a$ rental rights in relation to children and teenagers. This appears 22 times in the draft platform for action. Young people are particularly vulnerable to unwanted pregnancies, sexual abuse and STDs, including HIV/AIDS and they need access to contraceptive services and knowledge.

It can never be a right for parents to make all decisions about what information or services their children should have in respect to SRH. Parents can be supportive and help their children, but they can also be condemning and create great difficulties for the young person. Youths have the right to information and education vital for their well-being. That is recognized in the convention on the Rights of the Child. In a time when STDs and unsafe abortions are common among young people, the right to means for prevention must be safeguarded as agreed in the ICPD. In the ICPD document parents are also mentioned but not so often and in more positively written paragraphs about parents as support and guidance. It is unethical and it is not a parental right to deny youth life-saving knowledge and services when the means are available for treatment and prevention.

\section{Family and families?}

The reality of the family structure and its different forms was denied in the Beijing draft by using "Family structure" only in the singular form. This is not only a matter of a plural "s" or not. It is a question of accepting that families can appear in many different forms, not only as nuclear family or traditional extended family. There are nowadays, for example, a growing number of female-headed households in many parts of the world. This was also very controversial in Cairo. The phrase "Families and other unions" created discussions and could not be accepted, as there was a fear that this would include homosexual families. The agreed text in Cairo was various forms of the family exist.

\section{Sexuality and gender}

In Prep Com 3 for the Beijing conference it was agreed that the gender perspective should mainstream the whole document. Whether this is a strength or not is in the long run dependent on how much focus governments and NGOs put on the issue. There is also a risk that it will disappear because it is no one's responsibility to see to it that it is there.

\section{Essential issues in the field of SRH}

The essential field of sexual and reproductive health and rights are important parts of women's lives which created a great deal of interest in the Cairo document and the Beijing draft and final documents.

In this field we find big threats to women's health, through pregnancies and STDs. 
Sexuality is also a part of life that is used to control women. But it is also a field where many problems can be solved through knowledge and access to services.

- SRH is one important part of empowerment of young people and women.

- Sexual and reproductive health education

- Access to sexual and reproductive health services

- Condom use and promotion of safe sex

- Information and service for adolescents

- Women's right to control their own fertility

- Sexual and reproductive rights

- Unsafe abortion and unwanted pregnancy

- Male responsibility

All these areas are more or less controversial, but they appear in both documents, but are often in parentheses in the Beijing draft.

\section{Youth and their needs and rights}

Youth is a very important group that risked being rejected by the Beijing conference. Governments must deal with the most burning problems for youth. At UN conferences it is often a question of choosing between supporting young people or supporting the handful of countries that raise more and more obstacles against young people's rights.

Burning issues for youth are:

- Lack of knowledge

- Lack of self-esteem

- Lack of gender equality

- Sexuality

- Pregnancies

- STDs

- Contraceptives

- Unsafe abortion

- The SRH rights of young girls

- Lack of "youth-friendly" services

We need to both create awareness among youth about these things and get them accepted as important for youth in society. In order to deal successfully with these issues it is necessary to influence values and attitudes in society, to provide sex education and access to services. All these areas must be dealt with if we are to succeed in handling these burning issues.

In the following I have quoted parts of the documents. The quotes from the draft for Beijing are word for word, meaning that all the parentheses are there in order to show which parts were negotiated in Beijing. When I compare exact quotes I have used italics.

\section{Girls' rights in the documents}

At Prep Com 3 for Beijing some governments wanted to talk about female feticide instead of using the agreed terminology "prenatal sex selection". This was nothing more 
than a way to include a debate about abortion, instead of talking about prenatal sex selection. It is not common to talk about murder without meaning a living person, nor is it common language used about those who are not yet born.

The ICPD document mentions both prenatal sex selection and female infanticide, but the latter not in relation to fetuses. There is a need to realize that infanticide can result from not having access to contraceptives or abortion. Girls and young women often have very hard living conditions and they are much more vulnerable than boys. This is an effect of women's status all over the world and often means that girls get less food, less education, and face many more health threats than boys. The most obvious is the so called son-preference that leads to a situation were selection of sex is made before birth. It also leads to infanticide of small girls. This is often a result of maltreatment of baby girls. This is highlighted in both documents.

The basic condition for young girls is that their equal rights are recognized. But the following text had to be put in parentheses in the Beijing draft. Par 41

(If tomorrow's women are to become equal partners with men in social change and development, now is the time to (accord the girl child her rightful share of human dignity and opportunity and ensure the full enjoyment (respect) of all human rights (and fundamental freedoms) (including by universal ratification of the Convention of the Rights of the Child, of the girl child)

The draft for Beijing Par 41 They - girls - are often subjected to sexual and economic exploitation, violence and harmful practices such as (foeticide) infanticide (at conception), (prenatal sex selection), incest, female genital mutilation and early marriage.

ICPD Par 4.16 (a)To eliminate all forms of discrimination against the girl child and the root causes of son preference, which results in harmful and unethical practices regarding female infanticide and prenatal sex selection.

ICPD Par 4.23 Governments are urged to take the necessary measures to prevent infanticide, prenatal sex selection, trafficking in girl children and use of girls in prostitution and pornography.

\section{Men's lives and responsibilities in the documents}

All discussions about prevention and SRH have a focus on women and so it was in Cairo. This leads to a situation where the men were not discussed. Their needs and responsibilities were not taken into account. From time to time we even talk about the need of male involvement as if they, the men, were not already very deeply involved.

One of the problems that was problematic in the Beijing draft was a sentence talking about the need for men, also young men, to be provided with complete and accurate information and receive encouragement for safe and responsible sexual and reproductive behavior. Those who could not accept this wanted to recommend that boys and men abstain from sex before marriage. Not even the promotion of safe sex and responsible condom use was accepted in the draft.

In parentheses in the Beijing draft $\S 109,1$...design specific programs for boys, adolescents, (with the support and guidance of their parents,) (recognicing the rights duties and responsibilities of parents and other persons legally responsible for children and consistent with the Convention on the Rights of the Child) and men of all ages, aimed at providing (reliable) (complete and accurate) information and encouraging (abstinence until marriage as responsible sexual behavior.)

In Cairo the paragraphs about male responsibility were not very long or well formulated, but they had a content that needed to be developed and not denied. 


\section{Sexual rights in the documents}

In Cairo, reproductive rights was seen as a fundamental right, especially considering the alarming amount of rape and violence against women. One could think that this is basic, but in the Beijing draft it could not be accepted by those who wanted to go backwards instead of facing reality. This is a standpoint in the Beijing draft that leads to unsafe abortion, infertility, and death, combined with a lot of shame, guilt and fear. And it is certainly not a part of empowerment of women.

Sexual and reproductive rights are one of the most controversial questions in Cairo and in the Beijing draft it is shown in parentheses. Sexual and reproductive rights is a question of having the right to have control over one's own fertility and decide when, with whom and with which contraceptives one wants to have a sexual relationship. Sexual rights also means access to good and reliable information.

In Cairo this came up in Par 7.3 ...the basic right of all couples and individuals to decide freely and responsibly the number, spacing and timing of their children and to have the information and means to do so, and the right to attain the highest standard of sexual and reproductive health. It also includes their right to make decisions concerning reproduction, free of discrimination, coercion and violence, as expressed in human rights documents.

Principle 4 in ICPD Advancing gender equality and equity and the empowerment of women and the elimination of all kinds of violence against women, and ensuring women's ability to control their own fertility.

In the Beijing draft the term sexual and reproductive rights was not agreed on.

As to the question of rights and power, it is also important to take into account that a young woman too often has very few possibilities, if any, of demanding safe sex or saying no to sex. This lack of power leads to a lot of suffering and is an obstacle to the prevention of HIV and unwanted pregnancy. The Prep Com 3 for Beijing could not even accept that, Par. 99 stating: The unequal power in the relationships between men and women (are obstacles to the negotiation of safe sex.)

The right to have knowledge and accurate information is also a part of sexual rights. This is often denied to young people but in ICPD Par 7.41 it states:

Information and services should be made available to adolescents to help them understand their sexuality.

In ICPD Par 7.46: ...to protect and promote the rights of adolescents to reproductive health education.

In the Beijing draft similar words were in parentheses. Par 85k states: Remove legal and regulatory barriers to (sexual and reproductive health) education within formal education.

and in Par 108 e, Beijing Draft: (...information designed to ensure that women and men, particularly young people, can acquire knowledge about their health, especially information on sexuality and reproduction...)

Added to this is a sentence about the right and the duties of the parents. The question then arises whether also adult men and women have to ask their parents if it is all right for them get information.

\section{Power and fertility in the documents}

Examples from the Beijing draft:

Par 94: (The limited power many women have over their sexual and reproductive lives.) as well as (The right for all women to control their own fertility is basic to their empowerment.) were shown in parentheses. 
ICPD has wording about the limited power many women and girls have over their SRH and about the ability of women to control their own fertility.

\section{Sexual and reproductive health education in the documents}

The sentence in the Beijing draft in parentheses, Par 76 (The lack of sexual and reproductive health education has a profound impact on women and men.) This sentence is not acceptable without also pointing out the responsibilities, rights, and duties of parents or other legally responsible persons.

ICPD Par 7:36 ensures that...women and men have access to information, education and services needed to achieve good sexual health and exercise their reproductive rights and responsibilities.

The Beijing draft talked in Par $85 \mathrm{k}$ about removing the legal and regulatory barriers for education regarding (women's health issues ) instead of using the language agreed in Cairo, namely sexual and reproductive health education.

In the Cairo document it is pointed out that sexual and reproductive health education is a specific need for adolescents: In ICPD $7.46 \ldots$ protect and promote the rights of adolescents to reproductive health education, information and care.

\section{Quality of care}

Wording that described women's poor access to privacy and full information were not accepted in the Beijing draft, e.g., the following text was in parentheses: Par. 104 (Women are frequently not treated with respect, nor are they guaranteed privacy and confidentiality, nor do they always receive full information about options and services available.)

The Cairo document was very clear in expressing the need to improve quality of care. Privacy, confidentiality and the need for training in skills for interpersonal counseling were pointed out in chapter 7 .

\section{Privacy and confidentiality also for young girls}

Par 95 in the Beijing draft is shown in parentheses: (Counseling and access to sexual and reproductive health information and services for adolescents are still inadequate or lacking completely, and a young woman's right to privacy, confidentiality, respect and informed consent is often not considered.) This paragraph also mentions unsafe abortion.

In the Cairo document the same sentences about privacy and unsafe abortion were agreed language. Less than a year later, we were forced to take up the discussion all over again. It is especially the term 'unsafe abortion" that the Vatican did not accept. They say that all abortions are unsafe.

\section{The use of contraception in the documents}

\section{Condoms}

In the Cairo document, condoms and contraceptive drugs were pointed out as being positive in relation to prevention and in $\mathrm{Par} 8.35$ it was recommended to make 
them widely available, affordable and included in all essential drug lists. Only the Vatican state made a reservation against this.

In the Beijing draft document not even this is agreed text. (Unprotected sexual relationships) in Par 95, was not accepted wording. But this is a technical term which just describes intercourse without any contraception. It is not accepted by those who are skeptical to contraceptives as such. A fact to remember is that the Pope does not even accept condoms as protection against HIV/AIDS.

\section{Other contraceptives}

In the Beijing draft there is a text, Par $110 \mathrm{e}$, which states that women should be (informed about data which show that hormonal contraception, abortion and promiscuity increase the risk of developing cancers and infections of the reproductive tract so that they can make informed decisions about their health.)

This is a paragraph that will only scare people and it is not based on facts. There are several results showing that modern contraceptives also protect against diseases and that they prevent the likelihood of unsafe and dangerous abortions. The serious side-effects are few. The purpose of this kind of text is to stress morals and raise doubts about using contraceptive methods or having sex.

\section{Unwanted pregnancy}

Safe and legal abortion was an important issue in Cairo and also in Beijing also, Par $107 \mathrm{j}$ is shown in parentheses. (Recognize and deal with the health impact of unsafe abortion as a major public health concern as agreed in ICPD.)

It is well known that unsafe abortion is estimated to cause $24 \%$ of all maternal deaths in Latin America and $12-13 \%$ in Asia and Africa.

The text in Cairo was a result of many days negotiations and agreed on by an overwhelming majority of the governments. The Cairo document accepted unsafe abortion as a major health problem and talked about prevention and caretaking of those who had infections or bleeding after induced abortion. It also pointed out that where abortion is not against the law, such abortions should be safe.

\section{Are these kinds of UN documents useful?}

What is agreed in UN documents can be used in different ways. They can be used by those who want to change society and people's living conditions but can also be used by those who want to do the opposite. In Cairo, the governments agreed on many things that can be useful for achieving fruitful preventive work among youth and that can be helpful in order to reduce maternal death and morbidity.

Before Beijing there was a great risk that these steps forward would be left behind. Had that been the result of the Women's conference in Beijing it would have had severe consequences not only for women's sexual and reproductive health but also for women's possibilities of influencing their own lives. This is why it was important to hold fast to the agreements already made, and to always relate them to reality. To show that they are useful tools for those working for better conditions for individuals all over the world. That is why it is important to describe the most common problems in this field. 
What happened in Beijing?

Prep Com 3 came out with a text where only about $60 \%$ was agreed. The Vatican State and its friends had not even accepted the Cairo language, ICPD. But the time up to the conference in Beijing was well used by women from all over the world. Women's networks and NGOs especially in Africa and Latin America put a lot of pressure on their own governments to adhere to what they signed in Cairo. This also had an effect on the Vatican and its friends. When the conference started the Vatican and others took a step backwards when accepting the Cairo language. But they did not want to go further. They were more or less forced to take that position in the name of consensus.

I will give a short summary of what happened in the most controversial questions, which are human rights, parental rights, abortion, the girl child, boys and men, youth, cultural norms, sexual orientation, the final decision, and the future.

\section{Human rights}

Most of the controversial paragraphs concerning human rights for women were solved in a extra pre meeting in New York in August. References from that meeting include references to both ICPD in Cairo and to the conference on human rights in Vienna. These are rights that often concern spheres of life that are related to sexuality, reproduction and control over one's own body and fertility. The question of sexual rights was left to Beijing to be solved.

Parental rights was one of the other areas that created debate, and after a lot of discussion in small, formal and informal groups there was an agreement founded on the UN convention, "the bill of rights of the child". The agreed sentence stresses the rights of children and the responsibility of parents. These paragraphs are mentioned four or five times in the document. This can be compared to the 22 times that were suggested in the draft.

The problem about whether family should be in the singular or not was solved in a similar way as in Cairo. In Par 30 of the Beijing document it states: In different cultural political and social systems various forms of the family exist.

Abortion was a question that took a lot of time in Cairo, but in Beijing it was quite easily decided to use the Cairo language ( $8: 25)$ and to add one sentence about reviewing laws that include penalties for women (107k). In relation to abortion it is worth mentioning that the conference did not agree to inform women about the risks with abortion, contraception, and promiscuity, as was suggested by Prep Com 3. Instead the decision was for a more neutral text about the right to information about factors that can increase the risk for cancer, etc.

The girl child Par 259-285, were used in Prep Com 3 by the Vatican as a way of arguing against abortion. This did not succeed in Beijing. All references to female feticide were removed and only the term prenatal sex selection was used. The document also stated that female genital mutilation and early marriage must be fought by governments.

Boys and men are only mentioned formally in one paragraph, $109 \mathrm{l}$. This Paragraph is related to HIV and aids prevention. It was agreed that it is important to promote voluntary abstinence and condoms.

Youth. There was a lot of anxiety about young people having access to contraceptives and sex education. But finally the description about young girls being denied necessary and high quality and confidential preventive services was accepted.

Cultural norms. All through the conference there was said to be a lack of cultural, religious, and traditional norms as well as spiritual and moral values. This was pointed 
out as a problem by the Vatican and the Islamic states. The EU was accused of not taking this into account. It is important to know that many of the governments from Sub-Saharan Africa supported the same standpoint as the EU.

A text about culture and religious norms was proposed in relation to the health section. But this was not accepted. If it had been accepted this could have been used to undermine the whole chapter. Now it is accepted in the declaration and that is bad enough.

The question about sexual rights was one of the most difficult to get consensus on and the solution was to not use the term sexual rights but to write something very similar to that in Par 97. This is the compromise that was accepted for sexual rights: The human rights of women include their right to have control over and decide freely and responsibly on matters related to their sexuality, including sexual and reproductive health, free from coercion, discrimination and violence. Equal relationships between women and men in matters of sexual relations and reproduction, including full respect for integrity of the person, require mutual respect, consent and shared responsibility for sexual behavior and its consequences.

Sexual orientation was a very controversial term which appeared four times in the draft. The discussion held to find a compromise took many hours and finally the chair person ruled that the term should not be included in the document. Countries like South Africa and Israel argued for the term in light of their experiences of discrimination and its effects. Even if the term as such is not included, Par 97 can be interpreted so that the right to have a different sexual orientation without being discriminated is also included. This was important as it was not possible even to open up a discussion like this in Cairo. So this shows that a lot can happen in one year.

Summary The conference took several steps forwards instead of backwards, as expected. It was possible to discuss words and formulations that were absolutely impossible to even mention just one year ago in Cairo. Such examples are sexual rights and sexual orientation. This shows that it takes time, but is possible to bring up almost anything on the UN Agenda.

It is also obvious that sexuality is a very interesting and engaging theme. One reason is perhaps that questions about sexuality can be very concrete. It can be seen as a threat on a personal level as it is easy to start to think about one's own wife or daughter. But it also shows that sexuality is used as a very effective way to control women.

Today there is a lot of acceptance for language about empowerment of women in the fields of economics, politics, the labor market, and society. But when these terms are concretized into specific demands, it will be as controversial as sexuality. This became obvious when the conference discussed inheritance in Par $274 \mathrm{~d}$. When talking about equal rights for men and women, for a woman to have an equal right to inherit could not be accepted by some of the Muslim countries because of their religious beliefs. This shows that when empowerment is concrete it is difficult for those who rely on lip service to accept it. This will be the challenge for the coming year.

The decision about the document from the Fourth Conference on Women was a consensus decision. But there were 22 to 25 countries that made reservations on different parts, mainly related to sexuality and family. The Vatican will later on submit a written reservation, so we today do not know what they will say. But they have already indicated that they will focus on the fact that they think that the document focuses too much on the individual. Besides the Vatican it was mostly smaller Catholic and Muslim countries that had reservations relating to different parts of the document.

This was a conference with a similar controversy to that in Cairo, namely between the "State of God" and the "Secularised state". The only north/south conflict that came up was in relation to the questions about additional resources and disarmament.

Many countries in the South pointed out that this was the fourth conference in re- 
cent years presenting a lot of demands for change, and that it is about time they were given additional resources. The governments in the North stressed that it is the responsibility of all governments to work for gender equality and that limited resources can be shared equally among genders.

Now it is time to use this document. It is possible to interpret the wording that comes as a result of consensus, but there is no one answer to what the wording means. There will be competition as to who gives relevant content and meaning to the wording. This will have importance for what we can do in the field of empowerment in the coming years. It is necessary to make the wording about empowerment concrete in all areas of life.

We must take this document and see which parts have to be used nationally in our different countries and to express what is needed to put into the foreign aids programs.

It is encouraging that it is possible to use two weeks of talking and get better results and understanding than we could ever have hoped. With this in mind it must be possible for the governments in Scandinavia to use the document for action and this must be done both by governments and NGOs. 